\title{
Magnetic properties of Fe1-xMnx/Fe nanocomposites
}

\author{
Anhøj, Thomas Aarøe; Jacobsen, Claus Schelde; Mørup, Steen
}

Published in:

Journal of Applied Physics

Link to article, DOI:

$10.1063 / 1.1650920$

Publication date:

2004

Document Version

Publisher's PDF, also known as Version of record

Link back to DTU Orbit

Citation (APA):

Anhøj, T. A., Jacobsen, C. S., \& Mørup, S. (2004). Magnetic properties of Fe1-xMnx/Fe nanocomposites. Journal of Applied Physics, 95(7), 3649-3654. https://doi.org/10.1063/1.1650920

\section{General rights}

Copyright and moral rights for the publications made accessible in the public portal are retained by the authors and/or other copyright owners and it is a condition of accessing publications that users recognise and abide by the legal requirements associated with these rights.

- Users may download and print one copy of any publication from the public portal for the purpose of private study or research.

- You may not further distribute the material or use it for any profit-making activity or commercial gain

- You may freely distribute the URL identifying the publication in the public portal

If you believe that this document breaches copyright please contact us providing details, and we will remove access to the work immediately and investigate your claim 


\title{
Magnetic properties of $\mathrm{Fe}_{1-x} \mathrm{Mn}_{\boldsymbol{x}} / \mathrm{Fe}$ nanocomposites
}

\author{
Thomas A. Anhøj, Claus S. Jacobsen, and Steen Mørup ${ }^{\text {a) }}$ \\ Department of Physics, Technical University of Denmark, DK-2800 Kgs. Lyngby, Denmark
}

(Received 27 October 2003; accepted 7 January 2004)

\begin{abstract}
We have prepared nanocomposites of mixtures of ferromagnetic $\alpha$-Fe and antiferromagnetic $\gamma-\mathrm{Fe}_{50} \mathrm{Mn}_{50}$ nanoparticles, and studied their magnetic and structural properties by magnetization measurements, Mössbauer spectroscopy, and x-ray diffraction. A sample consisting of a 1:1 mixture of the two materials showed enhanced coercivity, but almost negligible exchange bias at room temperature after field cooling from $520 \mathrm{~K}$. However, samples with higher content of $\gamma$ - $\mathrm{Fe}_{50} \mathrm{Mn}_{50}$ showed significant exchange bias. The mechanisms for exchange bias and enhanced coercivity in the system are discussed. (C) 2004 American Institute of Physics. [DOI: 10.1063/1.1650920]
\end{abstract}

\section{INTRODUCTION}

Since the discovery of exchange anisotropy in composites of ferro- and antiferromagnetic materials by Meiklejohn and Bean ${ }^{1,2}$ the subject has received considerable attention, ${ }^{3,4}$ and the phenomenon is utilized in, for example, spin valves, which have applications in read heads in modern computers. Most of the research and applications have been concentrated on thin film structures, which can be fabricated in a wellcontrolled way. Efforts have also been made to produce socalled exchange spring magnets in which the exchange coupling between hard and soft magnetic materials are utilized to produce permanent magnets with improved properties. ${ }^{5,6}$ Some of the proposed production methods are well suited only for preparation of small quantities of permanent magnets or require advanced preparation techniques. Furthermore, some of the produced materials are based on relatively expensive elements, e.g., rare earths. Therefore, it would be interesting if one could develop new types of magnets based on cheap materials and simple preparation techniques, which are applicable for large-scale production of permanent magnets. Recently it has been shown ${ }^{7-9}$ that magnetic materials with exchange bias can be produced by ball-milling mixtures of ferromagnetic and antiferromagnetic materials. Sort et al. ${ }^{8,9}$ studied mixtures of ferromagnetic metallic particles $(\mathrm{Co})$ and antiferromagnetic oxides $(\mathrm{NiO})$ or sulphides $(\mathrm{FeS})$. They observed a small exchange bias in the composites after field cooling from a temperature above the Néel temperature of the antiferromagnetic material. Moreover, the composites showed enhanced coercivity. Here, we report on studies of the magnetic properties of composites of metallic ferromagnetic and antiferromagnetic nanoparticles.

$\gamma-\mathrm{Fe}_{50} \mathrm{Mn}_{50}$ is an antiferromagnetic metallic material with a Néel temperature of about $490 \mathrm{~K}$, which is commonly used in spin valves, and it is known that it can give rise to a large exchange bias. ${ }^{3,4}$ Therefore, it is interesting to study the magnetic properties of composites consisting of nanoparticles of $\gamma-\mathrm{Fe}_{50} \mathrm{Mn}_{50}$ mixed with nanoparticles of a ferromagnetic material. In this study we have chosen metallic iron as the ferromagnetic material. Both $\mathrm{Fe}$ and $\mathrm{Mn}$ are relatively

${ }^{\text {a)} E l e c t r o n i c ~ m a i l: ~ m o r u p @ f y s i k . d t u . d k ~}$ inexpensive and the desired nanoparticles can conveniently be prepared by high-energy ball-milling, which is a relatively simple preparation technique that may be used for large-scale production. Because various chemical reactions may take place during ball-milling, we have followed the evolution in the materials by Mössbauer spectroscopy and x-ray diffraction.

The structure of $\mathrm{Fe}_{1-x} \mathrm{Mn}_{x}$ alloys does not only depend on the concentrations but also on the preparation technique. ${ }^{9-16}$ For $x \leqq 0.1$ the alloys form the bcc $\alpha-\mathrm{Fe}_{1-x} \mathrm{Mn}_{x}$ phase which is ferromagnetic at room temperature. In alloys with $0.1 \leq x \leq 0.6$ an antiferromagnetic fcc $\gamma-\mathrm{Fe}_{1-x} \mathrm{Mn}_{x}$ phase can be found. For $0.1 \leqq x \leqq 0.4$ the Néel temperature is lower than $295 \mathrm{~K}$, i.e., these alloys are paramagnetic at room temperature. For larger values of $x$ (up to $\sim 0.6$ ), the fcc $\gamma-\mathrm{Fe}_{1-x} \mathrm{Mn}_{x}$ phase is antiferromagnetic at room temperature.

\section{EXPERIMENT}

Samples were prepared in a planetary ball-mill (Fritsch Pulverisette 5) with tungsten carbide vial and balls, operating at $200 \mathrm{rpm}$. The vial has a volume of $250 \mathrm{~cm}^{3}$, and the nine balls weigh approximately $500 \mathrm{~g}$. Prior to the milling, the vial was flushed with argon for approximately $10 \mathrm{~min}$. After milling in argon, the vial was left to cool before it was opened. $\gamma-\mathrm{Fe}_{1-x} \mathrm{Mn}_{x}$ particles were prepared by mechanical alloying of a 1:1 atomic ratio mixture of $\mathrm{Mn}(>99 \%$ pure, particle size $<100 \mu \mathrm{m})$ and $\mathrm{Fe}(\geqslant 99.5 \%$ pure, particle size $10 \mu \mathrm{m})$ from Merck. In the following these samples, which only contain the $\gamma$-phase after sufficiently long milling time, will be termed $\gamma-\mathrm{Fe}_{50} \mathrm{Mn}_{50}$. The Fe nanoparticles were prepared from the same batch of iron powder. In both cases the sample-to-ball weight ratio was 1:20. The components were ball-milled dry for $25 \mathrm{~h}$. There was a tendency for the particles to adhere to the walls of the vial and to the balls, especially when ball-milling the mixture of $\mathrm{Fe}$ and $\mathrm{Mn}$. Therefore, after this first, dry ball-milling, the components were ball-milled for two hours with $20 \mathrm{ml}$ of ethanol. This loosened the particles, which had adhered to vial and balls, and the final product was a fine-grained powder. $\alpha-\mathrm{Fe} / \gamma-\mathrm{Fe}_{1-x} \mathrm{Mn}_{x}$ composites were prepared from mixtures 
of the two components, which were either mixed thoroughly by hand using a spatula, or ball-milled with a sample-toball weight ratio of 1:250, and with $10 \mathrm{ml}$ of ethanol added in order to prevent adhesion to vial and balls.

$\mathrm{X}$-ray diffraction $(\mathrm{XRD})$ was performed using a Phillips PW1050 powder diffractometer with a $\mathrm{Cu}$ X-ray tube, and with a graphite monochromator placed between sample and detector.

Mössbauer spectra were recorded with conventional constant acceleration spectrometers in transmission geometry using ${ }^{57} \mathrm{Co} / \mathrm{Rh}$ sources. Isomer shifts are given relative to $\alpha$-Fe at room temperature.

Magnetization measurements were performed with a homemade $69 \mathrm{~Hz}$ Foner vibrating sample magnetometer (VSM). The instrument was calibrated by measuring the known saturation moment of a $31.7 \mathrm{mg}$ polycrystalline Nisample. Measurements were carried out at room temperature in the magnetic field range from -1.25 to $+1.25 \mathrm{~T}$, on powdered samples of approximately $80 \mathrm{mg}$ in cylindrical acrylic or copper sample containers sealed off with lids. Field cooling was carried out in the VSM oven by cooling the samples at approximately $10 \mathrm{~K} \mathrm{~min}^{-1}$ to room temperature in an applied field of $1.0 \mathrm{~T}$. Information about saturation magnetization, coercivity, exchange bias, and remanence were extracted from the obtained hysteresis loops. The saturation magnetization $\sigma_{S}$ was calculated as the mean of linear extrapolations of high field data points $\left(1.00 \mathrm{~T}<\mu_{0} H\right.$ $<1.25 \mathrm{~T}$ ) to zero field, for positive and negative fields. The intrinsic coercive field strength $H_{\mathrm{Ci}}$ and the exchange bias field strength $H_{E}$ were calculated from interpolations of data points around zero magnetization, for positive and negative fields. As exchange biased hysteresis loops are nonsymmetric, the remanent magnetization upon magnetization in a high positive field $\sigma_{R}^{+}$is the point of interest, and was found by interpolation of data points around zero field for positive magnetization.

\section{RESULTS}

Figure 1 shows room temperature Mössbauer spectra of a 1:1 (atomic ratio) mixture of $\mathrm{Fe}$ and $\mathrm{Mn}$ after various ballmilling times. After $1 \mathrm{~h}$, the spectrum consists of a sextet that is essentially identical to that of pure metallic iron, i.e., no significant reaction has taken place. After 2 and $4 \mathrm{~h}$, a singlet with isomer shift of about $-0.1 \mathrm{~mm} \mathrm{~s}^{-1}$ appears in the spectra. After $25 \mathrm{~h}$, the spectrum consists of a sextet with a magnetic hyperfine field of $\sim 3 \mathrm{~T}$, an isomer shift of -0.1 $\mathrm{mm} \mathrm{s}^{-1}$, and negligible quadrupole shift. These parameters are characteristic for antiferromagnetic $\gamma-\mathrm{Fe}_{1-x} \mathrm{Mn}_{x}$ with $x$ $\approx 0.5$. ${ }^{13,16}$ The fcc structure of the phase was confirmed by $\mathrm{x}$-ray diffraction, and the antiferromagnetic ordering was confirmed by magnetic measurements. At intermediate milling times, e.g., after $10 \mathrm{~h}$, the spectrum contains all three components. The singlet can be explained by the presence of a paramagnetic, iron-rich $\gamma-\mathrm{Fe}_{1-x} \mathrm{Mn}_{x}$ alloy. The small discrepancies between data and fits may be explained by defects in the structures and, especially for intermediate milling times, by inhomogeneous distributions of $\mathrm{Fe}$ and $\mathrm{Mn}$ in the $\alpha$ - and $\gamma$-phases. The studies show that we can form the

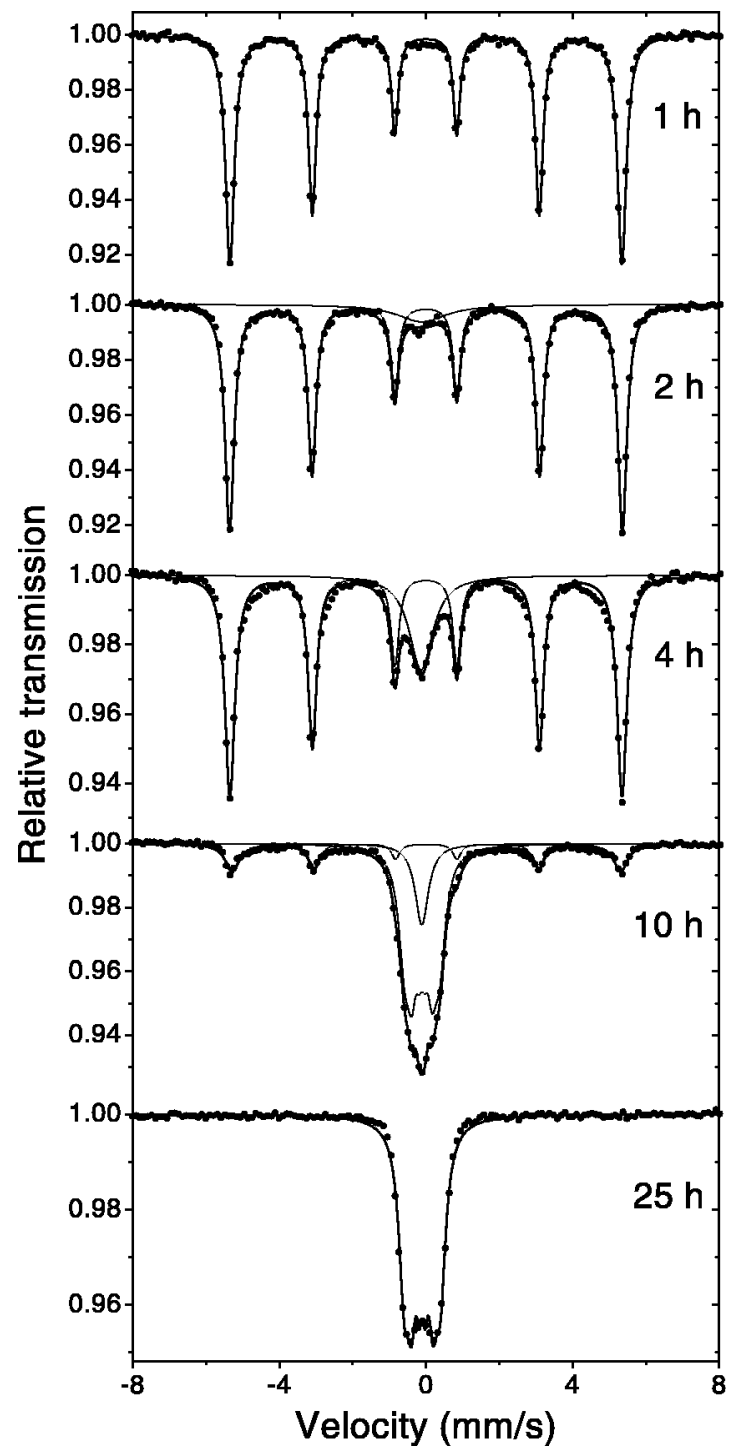

FIG. 1. Room temperature Mössbauer spectra of a 1:1 mixture (atomic ratio) of Fe and Mn powders obtained after the indicated ball milling times. The closed circles are data points, while the lines represent fits to the data.

antiferromagnetic $\gamma-\mathrm{Fe}_{50} \mathrm{Mn}_{50}$ phase by ball-milling the mixture of $\mathrm{Fe}$ and $\mathrm{Mn}$ powders for $25 \mathrm{~h}$. The crystallite size, estimated from the line broadening of the XRD spectra, was about $20 \mathrm{~nm}$, neglecting the contribution to the line broadening due to strain. We found that ball-milling of pure iron powder for $25 \mathrm{~h}$ resulted in a similar crystallite size. Neither Mössbauer spectra nor XRD spectra showed any indication of the presence of oxides or other impurity phases apart from small amounts of tungsten carbide from the ball-milling equipment.

The powders of $\alpha$-Fe and $\gamma-\mathrm{Fe}_{50} \mathrm{Mn}_{50}$, prepared as described above, were mixed (mixing ratio $1: 1$ by weight) and the mixture was ball-milled for milling times up to $10 \mathrm{~h}$ in order to create interfaces between $\alpha$-Fe and $\gamma-\mathrm{Fe}_{50} \mathrm{Mn}_{50}$ particles. Subsequently, the samples were heated at $520 \mathrm{~K}$ for 30 min in an applied magnetic field of $1.0 \mathrm{~T}$ and cooled in this field to room temperature. Figure 2(a) shows the coercivity at room temperature as a function of the time the mixture of $\alpha$-Fe and $\gamma-\mathrm{Fe}_{50} \mathrm{Mn}_{50}$ was milled. Data were obtained before 


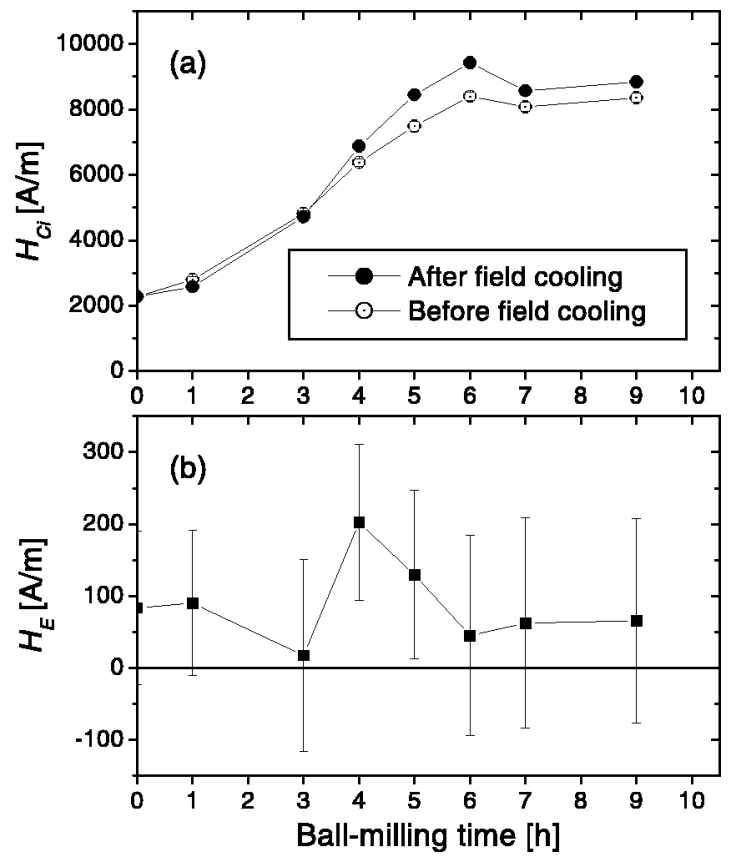

FIG. 2. The coercivity (a) and the exchange bias (b) of 1:1 mixtures of $\alpha$-Fe and $\gamma-\mathrm{Fe}_{50} \mathrm{Mn}_{50}$ nanoparticles as a function of the ball milling time. The data were obtained at room temperature.

and after the field cooling. For both types of samples, the coercivity increases with the milling time up to $6 \mathrm{~h}$. For longer milling times it decreases slightly. The exchange bias, shown in Fig. 2(b), is very small for all milling times, but for all samples there seems to be a tendency of positive values, possibly with a maximum around $4-5 \mathrm{~h}$. However, the coercivity, which initially decreases upon field cooling, increases in samples milled for four hours or longer. This suggests exchange coupling between the two components at these ball-milling times. After milling for seven hours or longer, the effect is weakened. The Mössbauer spectra of some of the samples, obtained before field cooling, are shown in Fig. 3 . As expected, the spectrum initially consists of the components due to $\alpha$-Fe and $\gamma-\mathrm{Fe}_{50} \mathrm{Mn}_{50}$. However, during ballmilling a singlet component with an isomer shift of about $-0.1 \mathrm{~mm} \mathrm{~s}^{-1}$ appears. This component can be ascribed to a paramagnetic iron-rich $\gamma-\mathrm{Fe}_{1-x} \mathrm{Mn}_{x}$ alloy. The relative intensity of the $\alpha$-Fe component decreases with milling time. These observations show that part of the $\alpha$-Fe is dissolved in the $\gamma-\mathrm{Fe}_{1-x} \mathrm{Mn}_{x}$ phase such that this phase becomes paramagnetic. However, for the longest milling times, a sextet with broad lines and a hyperfine field of about $30 \mathrm{~T}$ appears. This is indicative of a ferromagnetic iron-rich $\alpha-\mathrm{Fe}_{1-\mathrm{x}} \mathrm{Mn}_{\mathrm{x}}$ component. ${ }^{15,17}$ The relative areas of the ferromagnetic and the antiferromagnetic/paramagnetic components in the Mössbauer spectra as a function of the milling time are shown in Fig. 4(a), and the saturation magnetization is shown in Fig. 4(b). As illustrated in Fig. 4(a), the relative amount of ferromagnetic material ( $\alpha$-Fe and $\alpha-\mathrm{Fe}_{1-x} \mathrm{Mn}_{x}$ alloy) has a minimum at about $5 \mathrm{~h}$. This explains the minimum in the saturation magnetization at similar milling times. Mössbauer spectra of a sample ball-milled for four hours obtained before and after field cooling show a slight increase (from $48 \%$ to $51 \%$ ) of the ferromagnetic component upon field cooling.

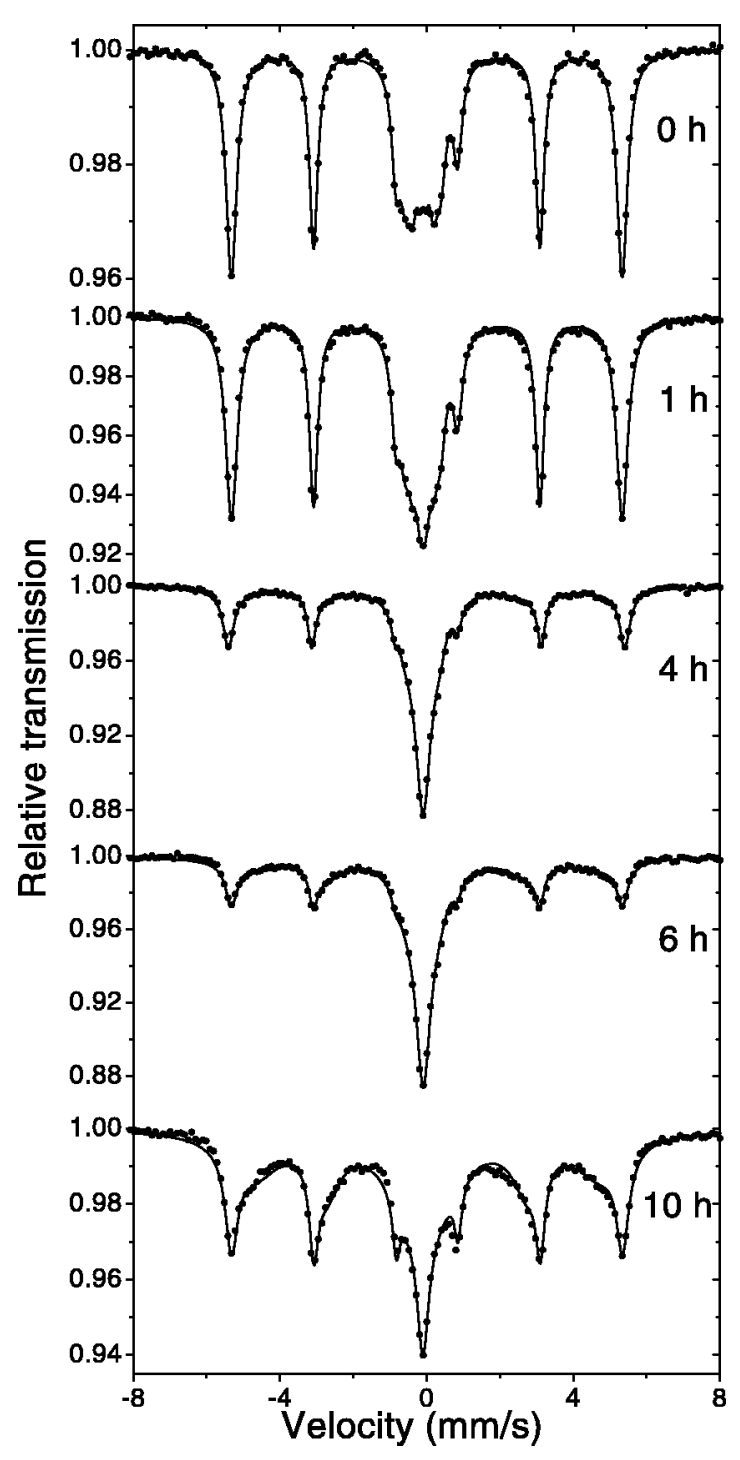

FIG. 3. Room temperature Mössbauer spectra of 1:1 mixtures of $\alpha$-Fe and $\gamma-\mathrm{Fe}_{50} \mathrm{Mn}_{50}$ nanoparticles obtained after the indicated ball milling times. The closed circles are data points, while the lines represent fits to the data.

The increase is comparable to the uncertainty, but magnetization measurements show a relative increase of saturation magnetization upon field cooling of similar magnitude.

The very small exchange bias [Fig. 2(b)] might be due to a small anisotropy energy of the antiferromagnetic $\gamma-\mathrm{Fe}_{1-x} \mathrm{Mn}_{x}$ particles related to their small size. We therefore studied the effect of increasing the relative amount of $\gamma-\mathrm{Fe}_{50} \mathrm{Mn}_{50}$ in the samples, which may result in larger $\gamma-\mathrm{Fe}_{1-x} \mathrm{Mn}_{x}$ particles. The exchange bias, the coercivity, the saturation magnetization, and the remanence as a function of the initial content of $\gamma-\mathrm{Fe}_{50} \mathrm{Mn}_{50}$, obtained after field cooling of samples mixed by hand and by ball-milling for $4 \mathrm{~h}$, are shown in Fig. 5. In samples with more than $80 \% \gamma-\mathrm{Fe}_{50} \mathrm{Mn}_{50}$ there is a very clear exchange bias both in samples of powders that are mixed without and with ball-milling [Fig. 5(b)]. The saturation magnetization of the hand-mixed samples [Fig. 5(c), open symbols] decreases linearly with increasing initial content of antiferromagnetic $\gamma-\mathrm{Fe}_{50} \mathrm{Mn}_{50}$ as expected. For the ball-milled samples [full symbols, Fig. 5(c)], the saturation magnetization is lower for most samples indicat- 


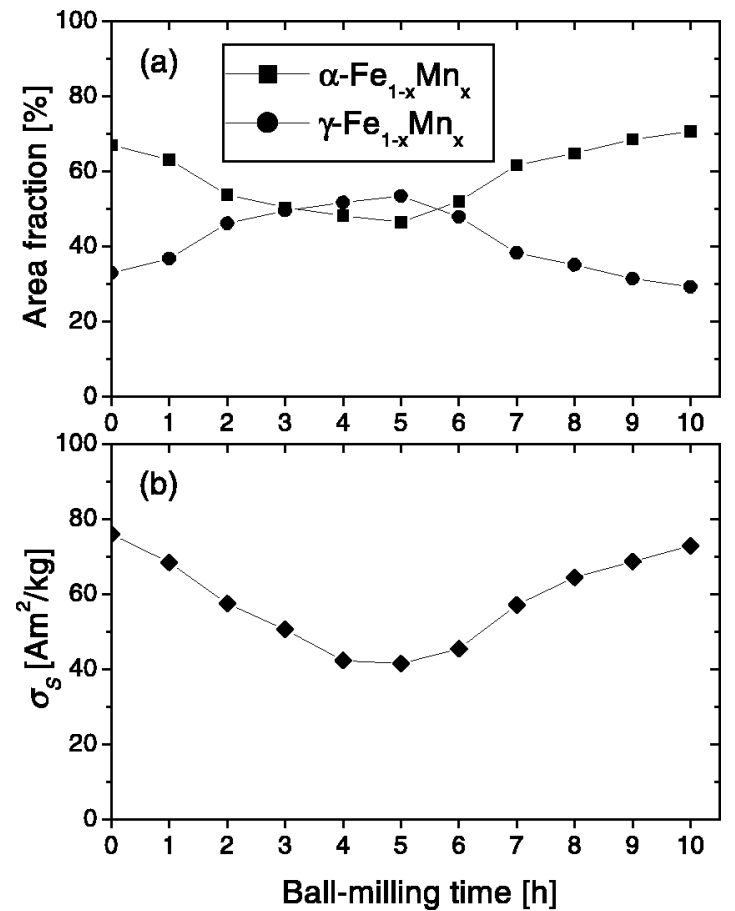

FIG. 4. (a) The area fractions of the $\gamma$ - $\mathrm{Fe}_{1-x} \mathrm{Mn}_{x}$ and $\alpha-\mathrm{Fe}_{1-x} \mathrm{Mn}_{x}$ components of the Mössbauer spectra shown in Fig. 3, plotted as a function of ball milling time. (b) The saturation magnetization of the same samples as a function of the ball milling time. The data were obtained at room temperature before field cooling.

ing that some of the $\alpha$-Fe has reacted with $\gamma$ - $\mathrm{Fe}_{50} \mathrm{Mn}_{50}$ such that the amount of ferromagnetic material has decreased. However, in the case of $95 \%$ of $\gamma-\mathrm{Fe}_{50} \mathrm{Mn}_{50}$, the saturation magnetization of the ball-milled sample is higher than that of the hand-mixed sample. The remanent magnetization [Fig.

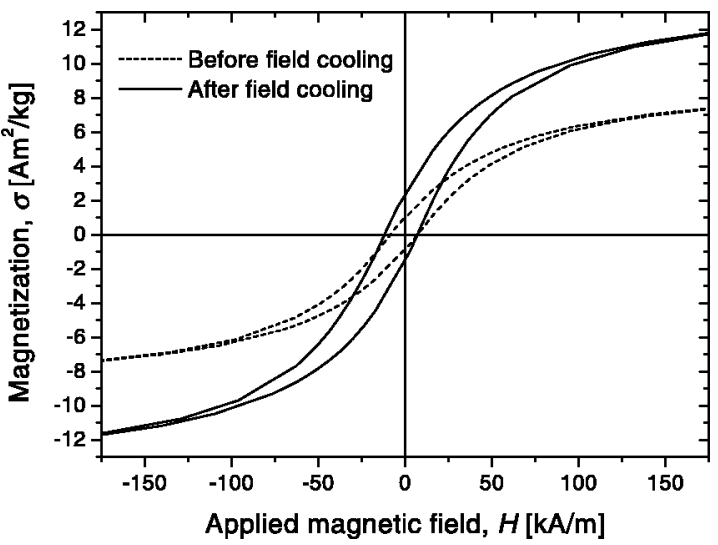

FIG. 6. Hysteresis loops obtained at room temperature for a sample with an initial $\gamma-\mathrm{Fe}_{50} \mathrm{Mn}_{50} / \alpha$ - $\mathrm{Fe}$ ratio of 10 . The dashed curve corresponds to the data obtained before field cooling. The full line shows the data obtained after field cooling.

5(d)] decreases much less with increasing $\gamma-\mathrm{Fe}_{50} \mathrm{Mn}_{50}$ content than the saturation magnetization.

Figure 6 shows hysteresis loops for samples with a $\gamma-\mathrm{Fe}_{50} \mathrm{Mn}_{50} / \alpha$-Fe ratio of 10 before and after field cooling. It can be seen that the field cooling results in a clearly visible exchange bias and an enhanced coercivity. Moreover, the saturation magnetization is significantly enhanced after field cooling. In order to find the reason for this we have obtained Mössbauer spectra of the two samples. The room temperature spectra are shown in Fig. 7. After field cooling, the relative intensity of the sextet due to $\alpha-\mathrm{Fe}_{1-x} \mathrm{Mn}_{x}$ has increased significantly (from $11 \%$ to $18 \%$ ). This explains the increase of the saturation magnetization.
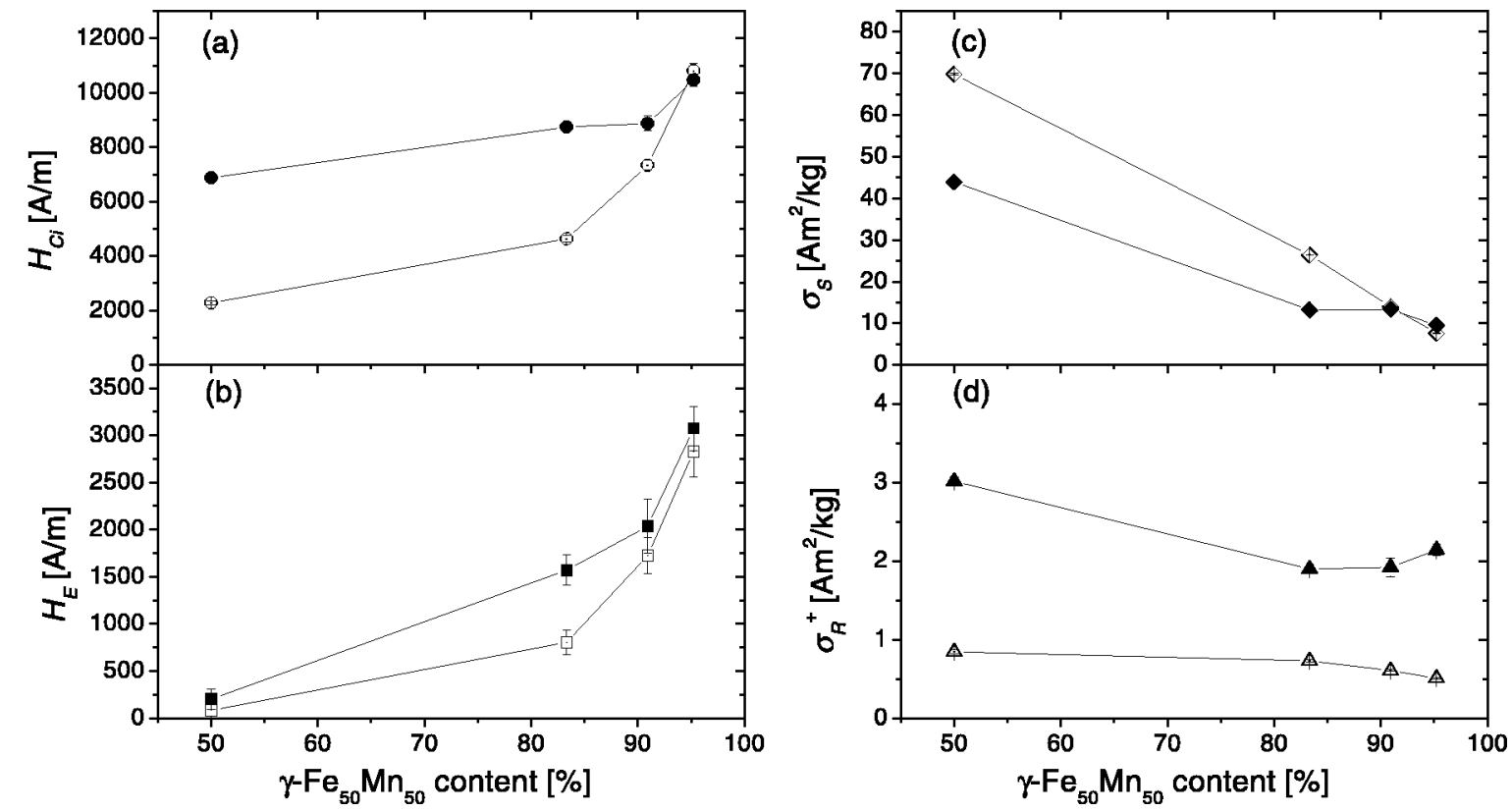

FIG. 5. The coercivity (a), the exchange bias (b), the saturation magnetization (c), and the remanent magnetization (d) of mixtures of $\alpha$-Fe and $\gamma$-Fe ${ }_{50} \mathrm{Mn}_{50}$ as a function of the content of $\gamma-\mathrm{Fe}_{50} \mathrm{Mn}_{50}$. The data were obtained at room temperature after field cooling. Open symbols correspond to samples prepared by mixing by hand. Full symbols correspond to data for samples that were mixed by ball milling in ethanol for $4 \mathrm{~h}$. 


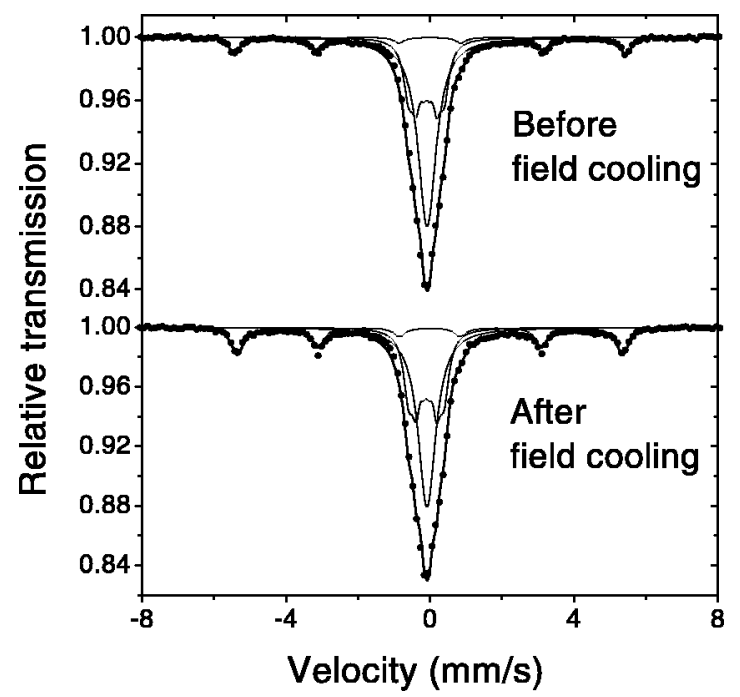

FIG. 7. Room temperature Mössbauer spectra of composites with a $\gamma$ - $\mathrm{Fe}_{50} \mathrm{Mn}_{50} / \alpha$-Fe ratio of 10 . The spectra were obtained before and after field cooling. The closed circles are data points, while the lines represent fits to the data.

\section{DISCUSSION}

The Mössbauer and X-ray studies show that one can easily prepare nanostructured $\alpha$-Fe and $\gamma-\mathrm{Fe}_{50} \mathrm{Mn}_{50}$ by use of ball-milling. After ball-milling of the mixture of the two phases for a short period of time, one might expect that interfaces between the two phases should have been formed, such that there should be strong exchange coupling between many of the ferromagnetic and antiferromagnetic nanoparticles, which might result in a significant exchange bias after the field cooling procedure. However, as seen in Fig. 2, the exchange bias is almost negligible in the 1:1 mixture of the two phases, but there is an increase of the coercivity. It is likely that the absence of a significant exchange bias is related to the small size of the antiferromagnetic particles. Because the magnetic anisotropy energy of the antiferromagnetic $\gamma-\mathrm{Fe}_{50} \mathrm{Mn}_{50}$ particles decreases with decreasing particle size, the energy required to reverse the sublattice magnetization will be small. Thus, when the magnetization direction of a neighboring ferromagnetic particle is reversed because it is exposed to an external field, the exchange coupling at the interface may be sufficient to reverse the sublattice magnetization in the antiferromagnetic nanoparticle. In this case, the coupling of the ferromagnetic particles to the antiferromagnetic ones will mainly give rise to an enhanced coercivity, as we have observed.

Another factor, which probably affects the exchange interactions, is the paramagnetic Fe-rich $\gamma-\mathrm{Fe}_{1-x} \mathrm{Mn}_{x}$ phase, which is formed during milling of the mixture of $\alpha$-Fe and $\gamma-\mathrm{Fe}_{50} \mathrm{Mn}_{50}$ nanoparticles. In the Mössbauer spectra, shown in Fig. 3, it constitutes about $40 \%$ of the area after ballmilling the 1:1 mixture of $\gamma-\mathrm{Fe}_{50} \mathrm{Mn}_{50}$ and $\alpha$-Fe for 4 and 6 h. In the spectra of the 1:10 mixture, shown in Fig. 7, it constitutes about $54 \%$ before field cooling and $44 \%$ after field cooling. It is likely that this phase can separate ferromagnetic $\alpha$-Fe and antiferromagnetic $\gamma-\mathrm{Fe}_{1-x} \mathrm{Mn}_{x}$ grains. The presence of such a paramagnetic phase can therefore seriously reduce the exchange coupling between the ferromagnetic and the antiferromagnetic grains. The migration of Fe atoms into the $\gamma-\mathrm{Fe}_{50} \mathrm{Mn}_{50}$ phase may also have another consequence. As the Fe concentration in the phase increases, and the Néel temperature decreases towards room temperature, the anisotropy decreases, resulting in a smaller exchange bias.

When the relative amount of $\gamma-\mathrm{Fe}_{50} \mathrm{Mn}_{50}$ is increased, a clear exchange bias appears in the field-cooled samples along with an increase of the coercivity. In samples that predominantly consist of antiferromagnetic $\gamma$ - $\mathrm{Fe}_{50} \mathrm{Mn}_{50}$ particles these will presumably form large aggregates with larger anisotropy energy than the individual particles. This could explain the increase of the exchange bias with increasing initial content of $\gamma-\mathrm{Fe}_{50} \mathrm{Mn}_{50}$ in the samples.

Although it is found that the ball milling of the composites can result in formation of a paramagnetic $\gamma-\mathrm{Fe}_{1-x} \mathrm{Mn}_{x}$ phase, the results given in Figs. 3 and 4 show that extended ball milling can increase the amount of ferromagnetic $\alpha-\mathrm{Fe}_{1-x} \mathrm{Mn}_{x}$ and this may improve the magnetic properties. As shown in Figs. 6 and 7, heat treatment of a sample with a $\gamma-\mathrm{Fe}_{50} \mathrm{Mn}_{50} / \alpha$-Fe ratio of 10 can also lead to the formation of ferromagnetic $\alpha-\mathrm{Fe}_{1-x} \mathrm{Mn}_{x}$, resulting in an enhanced saturation magnetization.

\section{CONCLUSIONS}

The present study has shown that it is possible to produce nanocomposites consisting of mixtures of $\gamma-\mathrm{Fe}_{1-x} \mathrm{Mn}_{x}$ and $\alpha$-Fe nanoparticles with enhanced coercivity and a nonzero exchange bias after field cooling. In order to understand the changes in magnetic properties during ball-milling and heat treatments, it is important to follow the structural evolution during ball-milling and heat treatments. Mössbauer spectroscopy is particularly useful for studies of such reactions because it can be used to distinguish, for example, between antiferromagnetic and paramagnetic $\gamma-\mathrm{Fe}_{1-x} \mathrm{Mn}_{x}$. The formation of a paramagnetic $\gamma-\mathrm{Fe}_{1-x} \mathrm{Mn}_{x}$ phase presumably is one of the reasons for the low exchange bias in samples with an initial 1:1 ratio of the two phases. The small anisotropy energy of the antiferromagnetic $\gamma-\mathrm{Fe}_{1-x} \mathrm{Mn}_{x}$ particles is another probable reason. Samples with a larger initial fraction of $\gamma-\mathrm{Fe}_{50} \mathrm{Mn}_{50}$ show unambiguously an exchange bias, both after mixing particles by hand and after ball-milling. In these samples it was also found that the amount of ferromagnetic material increased during the heat treatment in connection with the field cooling, such that these samples have an enhanced magnetization as well as a significant exchange bias and enhanced coercivity. It is likely that further studies of the influence of the initial composition, ball-milling conditions, and heat treatments on the magnetic properties of the composites can lead to synthesis procedures that can be used to make nanocomposites with larger coercivity and exchange bias.

\section{ACKNOWLEDGMENTS}

The work was supported by the Danish Technical Research Council and the Danish Natural Science Research Council. 
${ }^{1}$ W. H. Meiklejohn and C. P. Bean, Phys. Rev. 102, 1413 (1956).

${ }^{2}$ W. H. Meiklejohn and C. P. Bean, Phys. Rev. 105, 904 (1957).

${ }^{3}$ J. Nogués and I. K. Schuller, J. Magn. Magn. Mater. 192, 203 (1999).

${ }^{4}$ A. E. Berkowitz and K. Tekano, J. Magn. Magn. Mater. 200, 552 (1999).

${ }^{5}$ E. F. Kneller and R. Hawig, IEEE Trans. Magn. 27, 3588 (1991).

${ }^{6}$ E. E. Fullerton, J. S. Jiang, and S. D. Bader, J. Magn. Magn. Mater. 200, 392 (1999).

${ }^{7}$ D. S. Geoghegan, P. G. McCormick, and R. Street, Mater. Sci. Forum 179-181, 629 (1995).

${ }^{8}$ J. Sort, J. Nogués, X. Amils, S. Suriñach, J. S. Muñoz, and M. D. Baró, Appl. Phys. Lett. 75, 3177 (1999).

${ }^{9}$ J. Sort, J. Nogués, X. Amils, S. Suriñach, J. S. Muñoz, and M. D. Baró, J. Magn. Magn. Mater. 219, 53 (2000).

${ }^{10}$ A. A. Yousif, M. E. Elzain, A. Rais, and P. Terzieff, Hyperfine Interact. 94, 2295 (1994).
${ }^{11}$ T. Liu, H. Y. Liu, Z. T. Zhao, R. Z. Ma, T. D. Hu, and Y. N. Xie, Mater. Sci. Eng., A 271, 8 (1999).

${ }^{12}$ V. V. Tcherdyntsev, S. D. Kaloshkin, I. A. Tomilin, E. V. Shelekhov, and Y. V. Baldokhin, Z. Metallkd. 90, 747 (1999).

${ }^{13}$ M. Uhrmacher, A. Kulinska, Y. V. Baldokhin, V. V. Tcherdyntsev, S. D. Kaloshkin, A. Maddalena, and G. Principi, Intermetallics 10, 571 (2002).

${ }^{14}$ M. Uhrmacher, A. Kulinska, Y. V. Baldokhin, V. V. Tcherdyntsev, S. D. Kaloshkin, A. Maddalena, and G. Principi, Hyperfine Interact. 136/137, 327 (2001).

${ }^{15}$ K. Sumiyama, N. Ohshima, and Y. Nakamura, Phys. Status Solidi A 98, 229 (1986).

${ }^{16}$ H. Ohno and M. Mekata, J. Phys. Soc. Jpn. 31, 102 (1971).

${ }^{17}$ C. Paduani, E. Galvão da Silva, G. A. Perez-Alcazar, and M. McElfresh, J. Appl. Phys. 70, 7524 (1991). 